\title{
Produtividade da soja no cerrado influenciada pelas fontes de enxofre ${ }^{1}$
}

\author{
Soybean grain yield in cerrado region influenced by sulphur sources
}

\author{
Dirceu Luiz Broch², Paulo Sergio Pavinato ${ }^{3 *}$, Jean Carlo Possentti ${ }^{3}$, Thomas Newton Martin ${ }^{4}$ e Erci Marcos Del \\ Quiqui $^{5}$
}

\begin{abstract}
Resumo - O enxofre é um componente de proteínas e aminoácidos em plantas, sendo exigido em boa quantidade por leguminosas, pelo alto acúmulo de proteínas nessas espécies. Com isso, este trabalho teve por objetivo verificar a influência de diferentes fontes de enxofre sobre a produtividade de grãos na cultura da soja. O experimento foi instalado na área experimental da Fundação MS, em Maracajú, MS, em três anos consecutivos no delineamento de blocos ao acaso, com quatro repetições, submetidas à análise de variância conjunta. Foram implantadas as cultivares BRS-133 (2002/03 e 2003/04) e CD 202 (2004/05). Como tratamento foram avaliados: as adições de enxofre na forma de superfosfato simples, MAP sulfurado + Sulfurgran, Sulfurgran, enxofre elementar, gesso granulado, Fosmag 509M6, gesso agrícola a lanço e testemunha, sem a aplicação. A soja responde à aplicação de enxofre em solos das regiões do cerrado brasileiro, sendo necessária, na maioria das vezes, a fertilização com este nutriente para obtenção de altas produtividades. A grande maioria das fontes de enxofre utilizadas foi eficiente em fornecer este nutriente para a soja, com destaque para a aplicação de MAP Sulfurado + Sulfurgran, Formag 509M6 e gesso agrícola a lanço, que promoveram as melhores produtividades de grãos. $\mathrm{O}$ enxofre elementar não foi eficiente em disponibilizar S para a cultura.
\end{abstract}

Palavras-chave - Soja. Plantas-efeito do enxofre. Cerrado brasileiro.

\begin{abstract}
Sulphur is a component of protein and aminoacids in plants, being required in an expressive amount by leguminous, as function of high protein levels in these plants. Then, this work aimed to verify the influence of different sulphur sources on soybean grain yield. The experiment was carried out at the experimental area of Fundação MS, Maracajú, MS, in three consecutive years in a randomized block design with four replications, submitted to variance analysis of group experiments. The cultivars used were BRS-133 (2002/03 and 2003/04) and CD 202 (2004/05). As treatments, it was evaluated the application of sulfur as Simple Superphosphate, MAP sulphured + Sulfurgran, Sulfurgran, elemental sulphur, granulated gypsum, Fosmag 509M6, agricultural gypsum throwed on surface, and a witness without application. Soybean crop answer is positive to soil applied sulphur in Brazilian cerrado soils, in most of the time to obtain higher grain yield. Most of S sources were efficient to provide this nutrient for soybean, highlighting the applications of MAP Sulphured + Sulfurgran, Formag 509M6 and agricultural gypsum, that promoted the highest soybean grain yield. Elemental sulphur was not efficient to provide available $\mathrm{S}$ for the crop.
\end{abstract}

Key words - Soybean. Plants-sulphur effect. Brazilian cerrado.

\footnotetext{
* Autor para correspondência

${ }^{1}$ Recebido para publicação em 24/06/2010; aprovado em 02/05/2011

Trabalho de pesquisa realizado na Fundação MS, de Maracajú-MS

${ }^{2}$ Fundação MS para pesquisa e difusão de tecnologias agropecuárias, Maracajú-MS, Brasil, dirceu.fms@cooagri.coop.br

${ }_{3}^{3}$ Universidade Tecnológica Federal do Paraná, Campus Dois Vizinhos, Dois Vizinhos-PR, Brasil, pavinato@utfpr.edu.br, jpossentti@utfpr.edu.br

${ }^{4}$ Departamento de Fitotecnia, Universidade Federal de Santa Maria, Santa Maria-RS, Brasil, martin.ufsm@gmail.com

${ }^{5}$ Centro de Ciências Agrárias, Universidade Estadual de Maringá, Umuarama-PR, Brasil, ercimarcos@hotmail.com
} 


\section{Introdução}

As exigências de enxofre (S) pelas culturas variam muito de acordo com a espécie e com a produtividade esperada. No grupo das culturas de média/alta exigência incluem-se as leguminosas, que, de um modo geral, são mais exigentes que as gramíneas, em função de seu teor mais elevado de proteínas (ALVAREZ et al., 2007; RHEINHEIMER et al., 2005). Em função disso, a soja é uma cultura exigente neste nutriente, e há possibilidade de resposta à adubação com $\mathrm{S}$, especialmente em áreas de cerrado.

A deficiência de $\mathrm{S}$ pode ser observada em algumas regiões do Brasil, especialmente em solos sob cerrado, em razão da baixa fertilidade do solo, associada à pequena quantidade de $\mathrm{MO}$, ao aumento da exportação de S pelos grãos, causados por produtividades elevadas, e à lixiviação de sulfato, acentuada pela aplicação de calcário e fósforo (RHEINHEIMER et al., 2005; VITTI et al., 2007).

Resultados de pesquisa com $\mathrm{S}$ não são muito freqüentes no Brasil, pois para se conseguir isolar o efeito deste nutriente é preciso trabalhar com produtos puros, e muitas vezes o $\mathrm{S}$ é ou foi aplicado nas áreas cultivadas via fertilizantes compostos, como nutriente secundário, caso dos sulfatos e superfosfatos simples. Resultados obtidos por Rheinheimer et al. (2005) evidenciaram que o uso de doses de $\mathrm{SO}_{4}^{-2}$ de até $60 \mathrm{~kg} \mathrm{ha}^{-1}$, via superfosfato simples, não afetam a produtividade das culturas, as quais foram cultivadas na seqüência nabo forrageiro/milho/trigo/soja/ canola/milho. Resultados semelhantes foram observados por Osório Filho et al. (2007) com os tratamentos citados anteriormente, não havendo resposta da soja a doses de fertilizantes sulfatados.

O superfosfato simples é um fertilizante de rápida solubilidade e com teor de $12 \%$ de $\mathrm{S}_{-} \mathrm{SO}_{4}^{-2}$ na sua composição, disponibilizando facilmente para as culturas, já outras fontes, como o $\mathrm{S}$ elementar, precisam sofrer algumas reações de oxidação no solo para ficarem disponíveis, sendo transformados $\mathrm{em} \mathrm{SO}_{4}^{-2}$. Pois, segundo Horowitz e Meurer (2006), as plantas somente conseguem absorver o S elementar aplicado no solo depois de sua oxidação a sulfato, oxidação esta catalisada por enzimas produzidas principalmente por microrganismos.

O gesso agrícola é uma importante fonte de enxofre às culturas. Nogueira e Melo (2003) verificaram que os teores de $\mathrm{S}$ disponível $\left(\mathrm{SO}_{4}^{-2}\right)$ na camada de 0 a $20 \mathrm{~cm}$ do solo aumentaram com a aplicação de gesso, porém houve deslocamento desse S em profundidade no perfil, ficando pouco efeito residual nesta camada para os anos seguintes. De acordo com os autores, isso ocorre em função da alta solubilidade do sulfato, sendo que altas precipitações podem promover a lixiviação deste nutriente para camadas mais profundas, ou até sair do sistema explorado pelas raízes. Ainda, concluíram que as doses de gesso agrícola não influenciaram a produtividade da soja, em Latossolo Vermelho de Jaboticabal, SP.

Ainda não existe uma referência no que diz respeito à dose ideal de $\mathrm{S}$ para as culturas. De acordo com EMBRAPA (2003), a recomendação para a cultura da soja, para a região Central do Brasil, é de $15 \mathrm{~kg}$ para cada $1.000 \mathrm{~kg}$ de grãos produzidos. Neste sentido, como há carência de pesquisas que abordem a utilização do $\mathrm{S}$ na cultura da soja, realizou-se este trabalho com o objetivo de verificar a influência de diferentes fontes de enxofre sobre a produtividade de grãos na cultura da soja.

\section{Material e métodos}

O presente trabalho foi conduzido durante três anos agrícolas consecutivos, 2002/2003, 2003/2004 e 2004/2005, na área experimental da Fundação MS, em Maracajú, Mato Grosso do Sul, em um Latossolo Vermelho Distroférrico de textura argilosa (EMBRAPA, 1999). A área utilizada estava há cinco anos sob sistema de plantio direto, em resteva de milheto. As características químicas e granulométricas do solo estão apresentadas na Tabela 1. Pelos dados, constata-se que o solo é bastante argiloso, com teor médio de MO na camada superficial, e com teor de $\mathrm{S}$ considerado abaixo do ideal para a soja, que seria de $10 \mathrm{mg} \mathrm{dm}^{-3}$, conforme CQFS RS/SC (2004).

A semeadura foi realizada na primeira quinzena de novembro, para os três anos consecutivos. A precipitação pluviométrica acumulada no período de cultivo, ou seja, de novembro a março de cada ano agrícola, foi de 735 ; 737 e $713 \mathrm{~mm}$ para os anos 2002/2003, 2003/2004 e $2004 / 2005$, respectivamente. No entanto, no último ano agrícola, as precipitações nos meses de fevereiro (76 mm) e março $(35 \mathrm{~mm})$ foram bem abaixo da média dos últimos 10 anos, de 155 e $103 \mathrm{~mm}$, respectivamente, o que reduziu a produtividade média da soja (FUNDAÇÃO MS, 2005). A temperatura média para a região é de $25{ }^{\circ} \mathrm{C}$ para o período de cultivo, sendo que a média das mínimas ocorre no mês de novembro $\left(19,5^{\circ} \mathrm{C}\right)$, enquanto que a média das máximas ocorre em março $\left(31,8^{\circ} \mathrm{C}\right)$.

Antecipando ao primeiro ano de implantação, aplicou-se 2,5 $\mathrm{t} \mathrm{ha}^{-1}$ de calcário dolomítico e $250 \mathrm{~kg} \mathrm{ha}^{-1} \mathrm{de}$ superfosfato triplo, a lanço, três meses antes da semeadura, objetivando elevar a saturação para $70 \%$ e corrigir a deficiência de P na camada de 0 a $20 \mathrm{~cm}$, que estava em $5 \mathrm{mg} \mathrm{dm}^{-3}$, considerado muito baixo (RAIJ et al., 1997). Devido ao K estar baixo no solo (CQFS RS/SC, 2004), aplicou-se em cobertura $200 \mathrm{~kg} \mathrm{ha}^{-1} \mathrm{de} \mathrm{KCl}$ em área total, no primeiro ano de condução do experimento. 
Tabela 1 - Análise granulométrica e química do solo antes da implantação do experimento, em 2002, e após os três anos de cultivo da soja, em 2005. Fundação MS. Maracajú, MS, 2008

\begin{tabular}{|c|c|c|c|c|c|c|c|c|c|c|c|c|}
\hline \multicolumn{13}{|c|}{ Antes da implantação do experimento (2002) } \\
\hline Prof. & $\mathrm{pH}$ & MO & P-res & K & $\mathrm{Ca}$ & $\mathrm{Mg}$ & $\mathrm{Al}$ & $\mathrm{H}+\mathrm{Al}$ & SB & $\mathrm{T}$ & & $J$ \\
\hline$(\mathrm{cm})$ & $\mathrm{CaCl}^{2}$ & $\%$ & $\mathrm{mg} \mathrm{dm} \mathrm{dm}^{-3}$ & \multicolumn{7}{|c|}{ - $\mathrm{cmol}_{\mathrm{c}} \mathrm{dm}^{-3}$} & \multicolumn{2}{|c|}{$(\%)$} \\
\hline $0-20$ & 4,9 & 2,9 & 5,0 & 0,14 & 2,2 & 1,2 & 0,1 & 4,2 & 3,54 & 7,74 & & 6 \\
\hline $20-40$ & 4,3 & 1,9 & 2,0 & 0,04 & 0,5 & 0,3 & 1,1 & 5,8 & 0,84 & 6,64 & & 3 \\
\hline $40-60$ & 4,4 & 1,6 & 2,0 & 0,04 & 0,4 & 0,3 & 0,9 & 4,7 & 0,74 & 5,44 & & 4 \\
\hline $60-80$ & 4,4 & 1,3 & 2,0 & 0,03 & 0,1 & 0,2 & 0,7 & 4,7 & 0,33 & 5,03 & & 7 \\
\hline Prof. & $\mathrm{S}$ & $\mathrm{Zn}$ & B & $\mathrm{Cu}$ & $\mathrm{Mn}$ & $\mathrm{Fe}$ & \multicolumn{6}{|c|}{ Granulometria (\%) } \\
\hline$(\mathrm{cm})$ & -------. & ----- & ----- $\mathrm{mg} \mathrm{dn}$ & 3 ----- & ----- & ------ & \multicolumn{2}{|c|}{ Areia } & \multicolumn{2}{|c|}{ Silte } & \multicolumn{2}{|c|}{ Argila } \\
\hline $0-20$ & 6,0 & 0,7 & 0,26 & 3,1 & 27,2 & 21 & \multicolumn{2}{|c|}{25} & \multicolumn{2}{|c|}{12} & \multicolumn{2}{|c|}{63} \\
\hline $20-40$ & 6,0 & 0,2 & 0,22 & 1,3 & 6,2 & 8 & \multicolumn{2}{|c|}{22} & \multicolumn{2}{|c|}{10} & \multicolumn{2}{|c|}{68} \\
\hline $40-60$ & 6,0 & 0,2 & 0,29 & 0,8 & 3,4 & 6 & \multicolumn{2}{|c|}{17} & \multicolumn{2}{|c|}{10} & \multicolumn{2}{|c|}{73} \\
\hline $60-80$ & 6,0 & 0,2 & 0,21 & 0,6 & 1,8 & 5 & \multicolumn{2}{|c|}{18} & \multicolumn{2}{|c|}{8} & \multicolumn{2}{|c|}{74} \\
\hline \multicolumn{13}{|c|}{ Após os três anos de experimento (2005) } \\
\hline Prof. & $\mathrm{pH}$ & MO & P-res & $\mathrm{S}$ & K & $\mathrm{Ca}$ & $\mathrm{Mg}$ & $\mathrm{Al}$ & $\mathrm{H}+\mathrm{Al}$ & SB & $\mathrm{T}$ & $\mathrm{V}$ \\
\hline$(\mathrm{cm})$ & $\mathrm{CaCl}^{2}$ & $\%$ & $\mathrm{mg} \mathrm{dm} \mathrm{m}^{-3}$ & $\begin{array}{cc}---- \\
\end{array}$ & 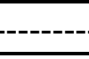 & $\begin{array}{c}--- \\
-\cdots\end{array}$ & $-\mathrm{cm}$ & $\mathrm{dm}^{-3}-$ & 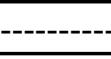 & - & $\begin{array}{l}--- \\
-\cdots\end{array}$ & $(\%)$ \\
\hline $0-20$ & 4,9 & 3,1 & 15,0 & 10,0 & 0,43 & 4,2 & 1,5 & 0,0 & 3,1 & 6,13 & 9,23 & 66 \\
\hline $20-40$ & 4,5 & 2,1 & 5,0 & 15,0 & 0,11 & 1,6 & 0,7 & 0,6 & 5,5 & 2,41 & 7,91 & 30 \\
\hline
\end{tabular}

A cultivar semeada nas duas primeiras safras foi a BRS-133 e na terceira safra foi a CD-202, todas tratadas com $150 \mathrm{~g} \mathrm{~L}^{-1}$ de Carbendazim $+300 \mathrm{~g} \mathrm{~L}^{-1}$ de Thiram, na dose de $100 \mathrm{~mL}$ do produto para cada $100 \mathrm{~kg}$ de sementes. As sementes também foram inoculadas com $300 \mathrm{~mL}$ de inoculante líquido a cada $50 \mathrm{~kg}$ de sementes, na semeadura de todas as safras. Também foram aplicados os micronutrientes cobalto (Co) e molibdênio (Mo) via semente, nas doses e formas recomendadas pelos fabricantes dos produtos. O boro foi aplicado no solo, na dose de $15 \mathrm{~kg} \mathrm{ha}^{-1}$ do produto comercial Granubor ${ }^{\circledR}$, em cobertura somente no primeiro ano de cultivo, juntamente com o $\mathrm{KCl}$.

As unidades experimentais foram compostas por parcelas de 27 metros quadrados com 5 fileiras de $12 \mathrm{~m}$ de comprimento e espaçamento de $0,45 \mathrm{~m}$ entre fileiras, no delineamento experimental de blocos casualizados, com quatro repetições. A área útil da parcela foi composta das três fileiras centrais, com quatro metros de comprimento, totalizando 5,4 metros quadrados. Os tratamentos foram constituídos de sete diferentes fontes de S e uma testemunha (TAB. 2). Nos tratamentos, desde o dois (Superfosfato simples) até o sete (Fosmag 509 M6) aplicou-se o S no sulco de semeadura, e no tratamento oito (Gesso agrícola), o produto foi aplicado a lanço logo antes da semeadura. Os demais nutrientes que compõem cada produto utilizado nas formulações foram balanceados com fontes puras de fertilizantes, para isolar o feito do $\mathrm{S}$ na produtividade da cultura. Esses tratamentos foram aplicados somente no primeiro ano de cultivo, sendo avaliados, no segundo e terceiro ano, o efeito residual desses produtos.

Após a colheita o material foi trilhado, as impurezas descontadas e a umidade corrigida para $13 \%$. Inicialmente, para cada um dos anos aplicou-se a análise de resíduo conforme Martin e Storck (2008). Realizou-se a análise de variância conjunta, com o auxílio do software de análise estatística Genes (CRUZ, 2001) e o teste de comparação múltipla de médias foi o de Skott-Knott ao nível de 1\% de significância de erro. 
Tabela 2 - Tratamentos utilizados como fonte de enxofre, fórmulas comerciais e quantidades utilizadas para completar a dose padrão de $40 \mathrm{~kg} \mathrm{ha}^{-1}$ de S. Fundação MS, Maracajú, MS, 2008

\begin{tabular}{ccccc}
\hline \multirow{2}{*}{ Trat. } & \multirow{2}{*}{ Fonte de Enxofre } & \multirow{2}{*}{ Formulado N-P2O5-K2O $+\mathrm{S}$} & Dose do formulado & Dose de S \\
\cline { 4 - 5 } & & $03-28-16+0,0$ & 319 & 0 \\
\hline 1 & Testemunha & $01-17-10+7,6$ & 521 & 40 \\
2 & Superfosfato simples & $05-23-13+10,1$ & 396 & 40 \\
3 & MAP Sulfurado + Sulforgran & $02-25-14+11,0$ & 361 & 40 \\
4 & Sulfurgran & $03-25-14+11,1$ & 359 & 40 \\
5 & Enxofre Elementar & $02-15-09+6,8$ & 586 & 40 \\
6 & Gesso granulado & $00-19-10+8,3$ & 482 & 40 \\
7 & Fosmag 509 M6 & $03-28-16+0,0$ & 319 & 40 \\
8 & Gesso agrícola - lanço & &
\end{tabular}

\section{Resultados e discussão}

Verificou-se que as pressuposições do modelo matemático não foram violadas em nenhum dos anos avaliados, conferindo assim qualidade experimental para a realização da análise de variância (MARTIN; STORCK, 2008). Verificou-se pelo teste do $F$ máximo que a relação entre o maior e o menor valor do quadrado médio do resíduo entre os diferentes anos foi de 1,72, o que indica que os anos podem ser analisados conjuntamente. A Tabela 3 apresenta resumo da análise de variância com as respectivas fontes de variação e quadrados médios com os respectivos níveis mínimos de significância.

A precisão experimental está apresentada por meio do coeficiente de variação, que não foi superior a 6,19 (TAB. 4), indicando que o experimento apresentou uma elevada qualidade tanto na avaliação nos diferentes anos quanto pela análise conjunta $(\mathrm{CV}=5,60)$. Carvalho et al. (2003) citam que coeficientes de variação aceitáveis para a variável produtividade de grãos de soja podem chegar a até $16 \%$.

Ao longo dos três anos de cultivo, a cultivar BRS 133 foi mais responsiva ao enxofre (2002/2003 e 2003/2004) que a cultivar CD 202 (2004/2005) quando se considera a média dos anos (TAB. 4). No entanto, a limitada disponibilidade de água no período final do ciclo para o ano agrícola 2004/2005 pode ter sido a principal causa da menor produtividade média, conforme citado na metodologia do trabalho, pois foi de 3462,4 e $3365,6 \mathrm{~kg} \mathrm{ha}^{-1}$ para os dois primeiros anos de cultivo, respectivamente, enquanto que no terceiro ano de cultivo a produção foi de $2743,3 \mathrm{~kg} \mathrm{ha}^{-1}$.

A produtividade de grãos foi maior nos tratamentos MAP + Sulfurgran (3), Fosmag 509M6 (7) Gesso agrícola à lanço (8), Gesso granulado (6), Sulfurgran (4) e Superfosfato simples (2), sendo a resposta em valor absoluto decrescente nesta ordem, mas todos os tratamentos apresentaram produtividade média dos três anos superior a $3100 \mathrm{~kg} \mathrm{ha}^{-1}$. Isso evidencia que a aplicação de enxofre em formas solúveis está sendo eficiente em disponibilizar este nutriente para as culturas, uma vez que a quantidade de $\mathrm{S}$ aplicada foi semelhante. $\mathrm{O}$ tratamento com enxofre elementar (5) foi inferior aos demais e não diferiu da testemunha (1), evidenciando ser uma fonte ineficaz de fornecimento deste nutriente à soja, para essas condições experimentais.

Tabela 3 - Resumo da análise de variância individual (para cada ano), fontes de variação (FV), com os respectivos graus de liberdade (GL), quadrados médios (QM), nível mínimo de significância (NMS), para a variável produtividade de grão $\left(\mathrm{kg} \mathrm{ha}^{-1}\right)$

\begin{tabular}{cccccccc}
\hline \multirow{2}{*}{ FV } & \multirow{2}{*}{ GL } & \multicolumn{2}{c}{2003} & \multicolumn{2}{c}{2004} & \multicolumn{2}{c}{2005} \\
\cline { 2 - 7 } & & QM & NMS & QM & NMS & QM & NMS \\
\hline Tratamento & 7 & $300046,5^{*}$ & $<0,001$ & $202982,8^{*}$ & 0,003 & $55885,98^{\text {ns }}$ & 0,09 \\
Bloco & 3 & $215617,5^{*}$ & 0,001 & $74293,5^{\text {ns }}$ & 0,195 & 14338,12 ns & 0,67 \\
Erro & 21 & 25144,07 & & 43350,64 & & 27335,83 & \\
\hline
\end{tabular}

* e ns: significativo e não significativo ao nível de $1 \%$ de significância de erro 
Tabela 4 - Análise conjunta dos dados da média de produtividade de grãos da soja, coeficiente de variação (CV) e diferença mínima significativa (DMS) a 1\%, ao longo dos três anos de cultivo, em função das diferentes fontes de enxofre. Fundação MS, Maracajú, MS, 2008

\begin{tabular}{|c|c|c|c|}
\hline Tratamento & Fonte de Enxofre & \multicolumn{2}{|c|}{ Média } \\
\hline 1 & Testemunha & \multicolumn{2}{|c|}{$2877,0 b^{*}$} \\
\hline 2 & Superfosfato simples & \multicolumn{2}{|c|}{$3147,5 \mathrm{a}$} \\
\hline 3 & MAP Sulfurado + Sulfurgran & \multicolumn{2}{|c|}{$3383,5 \mathrm{a}$} \\
\hline 4 & Sulfurgran & \multicolumn{2}{|c|}{$3178,0 \mathrm{a}$} \\
\hline 5 & Enxofre Elementar & \multicolumn{2}{|c|}{$2973,5 \mathrm{~b}$} \\
\hline 6 & Gesso granulado & \multicolumn{2}{|c|}{$3247,5 \mathrm{a}$} \\
\hline 7 & Fosmag 509 M6 & \multicolumn{2}{|c|}{3366,0 a } \\
\hline 8 & Gesso agrícola à lanço & \multicolumn{2}{|c|}{$3350,5 \mathrm{a}$} \\
\hline Anos agrícolas & Média & $\mathrm{CV}$ & DMS (1\%) \\
\hline $2002 / 03$ & 3462,4 & 4,58 & 459,40 \\
\hline $2003 / 04$ & 3365,6 & 6,19 & 603,20 \\
\hline $2004 / 05$ & 2743,3 & 6,03 & 479,00 \\
\hline Média & 3190,4 & 5,60 & \\
\hline
\end{tabular}

* médias não ligadas pela mesma letra diferem ao nível de 1\% de significância de erro pelo teste de Scott-Knott

Originalmente, os solos do cerrado brasileiro são pobres em nutrientes e em matéria orgânica. O solo da área experimental, um Latossolo Vermelho, apresentava média a baixa fertilidade, sendo muito responsivos à aplicação de S. Por outro lado, Nogueira e Mello (2003) não obtiveram resultado com a aplicação de gesso em um solo arenoso com baixa fertilidade (apenas 2,2\% de MO), da região de Jaboticabal, SP. Os autores verificaram que a aplicação de gesso agrícola causou aumento temporário nos teores de S-sulfato nas amostras de solo, mas este aumento foi sem efeito residual de um ano para outro na camada de 0 a $20 \mathrm{~cm}$, confirmando a alta mobilidade desse íon no perfil do solo. Essa mobilidade é confirmada no trabalho de Neis et al. (2010), onde foi observado aumento na disponibilidade de sulfato na camada de 20-40 cm quando comparado com camadas acima (5-10 e 10-20 cm), mas as doses de enxofre aplicadas não promoveram aumento na produtividade da soja.

Embora possa não haver resposta à aplicação de $\mathrm{S}$ em muitas áreas cultivadas pelo Brasil, é preciso ficar atento ao que acontece no solo, em função do $\mathrm{S}$ apresentar rápido deslocamento ao longo do perfil em profundidade, dando atenção especial para que a disponibilidade do elemento não possa se tornar limitante aos próximos cultivos. Nos dados obtidos após os três anos de experimento, em 2005 (TAB. 1), pode-se observar que a fertilidade do solo, de um modo geral, melhorou na área cultivada até a profundidade avaliada $(0 \mathrm{a} 40 \mathrm{~cm})$, com elevação nos teores disponíveis de $\mathrm{P}, \mathrm{K}, \mathrm{Ca}, \mathrm{Mg}$ e também da saturação por bases. Isso ocorreu em função da correção inicial da área e pela ciclagem de nutrientes via $\mathrm{MO}$, mantendo os nutrientes no sistema. Com relação ao $\mathrm{S}$ também houve aumento na disponibilidade dele no solo. É possível se detectar que houve deslocamento de $\mathrm{S}$ no perfil do solo, pois a disponibilidade é superior na camada de $20-40 \mathrm{~cm}$ em relação a 0-20 cm. Conhecendo o comportamento deste nutriente no solo, é de se esperar que a disponibilidade seja maior ainda nas camadas mais profundas, não avaliadas aqui.

Avaliando as alterações químicas do solo e a resposta da cultura da soja ao calcário e gesso aplicados na implantação do sistema de plantio direto em solo argiloso da região de Ponta Grossa, PR, Caires et al. (2003) concluíram que não houve resposta da soja, em três cultivos consecutivos. Os autores verificaram que a aplicação de gesso agrícola, associada ou não à calagem, na superfície ou com incorporação, não foi uma estratégia interessante para o estabelecimento da soja no sistema plantio direto, por não ocasionar melhoria na disponibilização de nutrientes e na distribuição radicular no perfil do solo, não afetando a produção de grãos, em estudos relacionando à aplicação de $\mathrm{S}$ via solo e via foliar. Já, Vitti et al. (2007) indicam que a aplicação de $\mathrm{S}$ via foliar aumenta a produção de grãos em soja, semelhantemente ao que ocorre com a aplicação de S no solo. Porém, as mesmas produtividades foram observadas quando se aplicou $20 \mathrm{~kg} \mathrm{ha}^{-1}$ de $\mathrm{S}$ no solo ou $6 \mathrm{~kg} \mathrm{ha}^{-1}$ via foliar, onde a eficiência da aplicação de $\mathrm{S}$ via foliar, com base no conteúdo de proteína solúvel total, foi superior a 
da aplicação via solo. Portanto, a avaliação da eficiência da fertilização com enxofre é um ponto que ainda precisa de estudos, a fim de melhorar o aproveitamento deste e de outros nutrientes pelas culturas.

\section{Conclusões}

1. A cultura da soja responde à aplicação de fontes solúveis de enxofre, mas a resposta normalmente se limita a solos pobres neste nutriente;

2. A grande maioria das fontes de $\mathrm{S}$ utilizadas foi eficiente em fornecer este nutriente para a soja, porém o enxofre elementar não foi eficiente em disponibilizar S para a cultura.

\section{Referências}

ALVAREZ, V. H. et al. Enxofre. In: NOVAIS, R. F. et al. (Ed) Fertilidade do solo. Viçosa, MG: Sociedade Brasileira de Ciência do Solo, 2007. p. 595-644.

CAIRES, E. F. et al. Alterações químicas do solo e resposta da soja ao calcário e gesso aplicados na implantação do sistema plantio direto. Revista Brasileira de Ciência do Solo, v. 27, n. 02, p. 275-286, 2003.

CARVAlHO, C. G. P. et al. Proposta de classificação dos coeficientes de variação em relação à produtividade e altura da planta de soja. Pesquisa Agropecuária Brasileira, v. 38, n. 02, p. 187-193, 2003.

COMISSÃO DE QUÍMICA E FERTILIDADE DO SOLO (CQFS RS/SC). Manual de adubação e de calagem para os Estados do Rio Grande do Sul e Santa Catarina. 10. ed. Porto Alegre: Sociedade Brasileira de Ciência do Solo,. 2004. 400 p.

CRUZ, C. D. Programa GENES: aplicativo computacional em genética e estatística versão Windows. Viçosa: UFV, 2001. 442 p.

EMPRESA BRASILEIRA DE PESQUISA AGROPECUÁRIA (EMBRAPA). Sistema brasileiro de classificação de solos. Brasília: EMBRAPA, 1999. 412 p.
EMPRESA BRASILEIRA DE PESQUISA AGROPECUÁRIA (EMBRAPA). Tecnologias de Produção de Soja Região Central do Brasil, Sistema de Produção, 1, Versão eletrônica, Jan/2003. Disponível em: <http://sistemasdeproducao.cnptia. embrapa.br>. Acesso em: 10 maio 2009.

FUNDAÇAO MS. Precipitações pluviométricas ocorridas nos núcleos experimentais da Fundação MS. 2005. Disponível em: <www.fundacaoms.org.br/request.php?73>. Acesso em: 01 abr. 2010.

HOROWITZ, N.; MEURER, E. J. Oxidação do enxofre elementar em solos tropicais. Ciência Rural, v. 36, n. 03, p. 822-828, 2006.

MARTIN, T. N.; STORCK, L. Análise das pressuposições do modelo matemático em experimentos agrícolas no delineamento blocos ao acaso. In: MARTIN, T. N.; ZIECH, M. F. (Org.). SEMINÁRIO: SISTEMAS DE PRODUÇÃO AGROPECUÁRIA, 2, 2008, Curitiba. Anais... Curitiba: UTFPR, 2008, p. 177-196. v. 1.

NEIS, L. et al. Gesso agrícola e rendimento de grãos de soja na região do sudoeste de Goiás. Revista Brasileira de Ciência do Solo, v. 34, n. 02, p. 409-416, 2010.

NOGUEIRA, M. A.; MELO, W. J. Enxofre disponível para a soja e atividade de arilsulfatase em solo tratado com gesso agrícola. Revista Brasileira de Ciência do Solo, v. 27, n. 04, p. $655-663,2003$.

OSÓRIO FILHO, B. D. et al. Deposição do enxofre atmosférico no solo pelas precipitações pluviais e respostas de culturas à adubação sulfatada em sistema plantio direto. Ciência Rural, v. 37, n. 03, p. 712-719, 2007.

RAIJ, B. VAN et al. Recomendações de adubação e calagem para o Estado de São Paulo. Campinas: Instituto Agronômico, 1997. 285 p. (Boletim Técnico, 100).

RHEINHEIMER, D. S. et al. Resposta de culturas à aplicação de enxofre e a teores de sulfato num solo de textura arenosa sob plantio direto. Ciência Rural, v. 35, n. 03, p. 562-569, 2005.

VITTI. G. et al. Assimilação foliar de enxofre elementar pela soja. Pesquisa Agropecuária Brasileira, v. 42, n. 02, p. 225-229, 2007. 